\title{
Aldehyde dehydrogenase 1A1 and gelsolin identified as novel invasion-modulating factors in conditioned medium of pancreatic cancer cells
}

\author{
Naomi Walsh*,1, Paul Dowling ${ }^{1}$, Norma O'Donovan, Michael Henry, \\ Paula Meleady, Martin Clynes
}

National Institute for Cellular Biotechnology, Dublin City University, Glasnevin, Dublin 9, Ireland

\section{A R T I C L E D A T A}

Article history:

Received 30 April 2008

Accepted 16 September 2008

Keywords:

ALDH1A1

GSN

Pancreatic cancer

Invasion

Conditioned media

2D DIGE MALDI-TOF MS

\begin{abstract}
A B S T R A C T
Conditioned medium (CM) from clonal sub-populations of the pancreatic cancer cell line, MiaPaCa-2 with differing invasive abilities, were examined for their effect on in vitro invasion. Conditioned medium from Clone \#3 (CM\#3) strongly promoted invasion, while CM from Clone \#8 (CM\#8) inhibited invasion in vitro. 2D DIGE followed by MALDI-TOF MS analysis of $\mathrm{CM} \# 3$ and $\mathrm{CM \# 8}$ identified 41 proteins which were differentially regulated; 27 proteins were down-regulated and 14 proteins up-regulated in the invasion-promoting $\mathrm{CM} \# 3$ when compared to $\mathrm{CM} \# 8$. Western blotting analysis confirmed the down-regulated expression of gelsolin and the up-regulation of aldehyde dehydrogenase 1A1 in CM\#3. Down-regulation of aldehyde dehydrogenase $1 \mathrm{~A} 1$ in Clone \#3 CM and gelsolin levels in Clone \#8 CM by siRNA transfection revealed an important involvement of these proteins in promoting and inhibiting invasion in these pancreatic cancer cell lines.
\end{abstract}

(c) 2008 Elsevier B.V. All rights reserved.

\section{Introduction}

Pancreatic cancer is one of the most lethal cancers and is the 8th leading cause of cancer-related deaths in Europe [1]. Pancreatic cancer is associated with poor prognosis, the rate of mortality being similar to that of the rate of incidence.

All-stage 5-year survival rate is less than 5\% [2,3]. Conventional approaches including, surgery, radiation, chemotherapy and combinations of these therapies, have had little effect on the survival rate of patients diagnosed with pancreatic cancer. Pancreatic cancer appears to be inherently resistant to a wide variety of chemotherapeutic agents, which can differ greatly and are unrelated with respect to molecular structure and target specificity. The malignant progression, invasion and metastasis of this cancer are complex and poorly understood. In this study, we investigated the proteomic profile of proteins from the conditioned media of two sub-clones of a pancreatic cancer cell line with varying in vitro invasive characteristics. Proteins released by pancreatic tumour cells may be detectable in bodily fluids such as urine, blood, serum and pancreatic ductal juice. Such proteins could be useful in early diagnosis, monitoring and perhaps even molecular classification of pancreatic tumours [4]. Proteomic analyses of pancreatic tissue, pancreatic juice as well as blood plasma and sera have been reported [5]. The main biomarker currently available for pancreatic cancer detection, CA19-9, has been demonstrated to be quite sensitive and specific in the diagnosis of this malignancy [6,7], however, this marker is not fully specific as false-positive or false-negative findings occur in patients with other gastrointestinal malignancies and also in patients with benign disease, particularly when associated with obstructive jaundice or cirrhosis, which may contribute to late diagnosis of pancreatic cancer. Approximately $10 \%$ of the population with the Lewis negative genotype are not able to produce CA 19-9,

\footnotetext{
* Corresponding author. Fax: +3537005484 .

E-mail address: naomi.walsh@dcu.ie (N. Walsh).

${ }^{1}$ Authors contributed equally.
} 
due to a deficiency in a fucosyltransferase specified by the Le gene that is involved in its synthesis [8]. Therefore, in a sub-set of patients, CA 19-9 expression will be falsely low even in the presence of advanced pancreatic cancer [9].

We previously isolated sub-clones of the human pancreatic adenocarcinoma cell line, MiaPaCa-2. This cell line was chosen as it displays modest invasion through matrigel, and could be easily cultured as single cell colonies. Two subclones, Clone \#3 and Clone \#8 displayed the largest differences in invasion compared to the parental cell line and were chosen for further analysis.

In this study, we compared proteins in the conditioned media of highly and poorly invasive sub-clones of the pancreatic cancer cell line, MiaPaCa-2, and identified many novel up-regulated and down-regulated proteins in our model. Furthermore, we investigated the functional role of aldehyde dehydrogenase $1 \mathrm{~A} 1$ and gelsolin in invasion by siRNA analysis and determined that these proteins may have a novel role in the invasive phenotype of pancreatic cancer.

\section{Materials and methods}

\subsection{Cell lines}

The human pancreatic cell line MiaPaCa-2 was obtained from the European Collection of Cell Cultures (ECACC, UK). BxPc-3, Panc-1 and AsPc-1 human pancreatic cancer cell lines were obtained from the American Type Culture Collection (ATCC, Rockville, MD, USA). Clone \#3 and Clone \#8 were obtained by single cell dilution in this laboratory. Briefly the parental cell line, MiaPaCa-2 was diluted to a concentration of 3 cells $/ \mathrm{ml}$ and $100 \mu \mathrm{l}$ plated onto each well of a 96 -well plate. After $24 \mathrm{~h}$ each well was studied for single cells, and allowed to grow into colonies. The colonies were then screened by invasion assay to assess their invasive abilities. Cells were maintained in a humidified atmosphere containing $5 \% \mathrm{CO}_{2}$ at $37{ }^{\circ} \mathrm{C}$ in DMEM supplemented with 5\% FCS (SigmaAldrich). All cell lines were free from Mycoplasma as tested with the indirect Hoechst staining method.
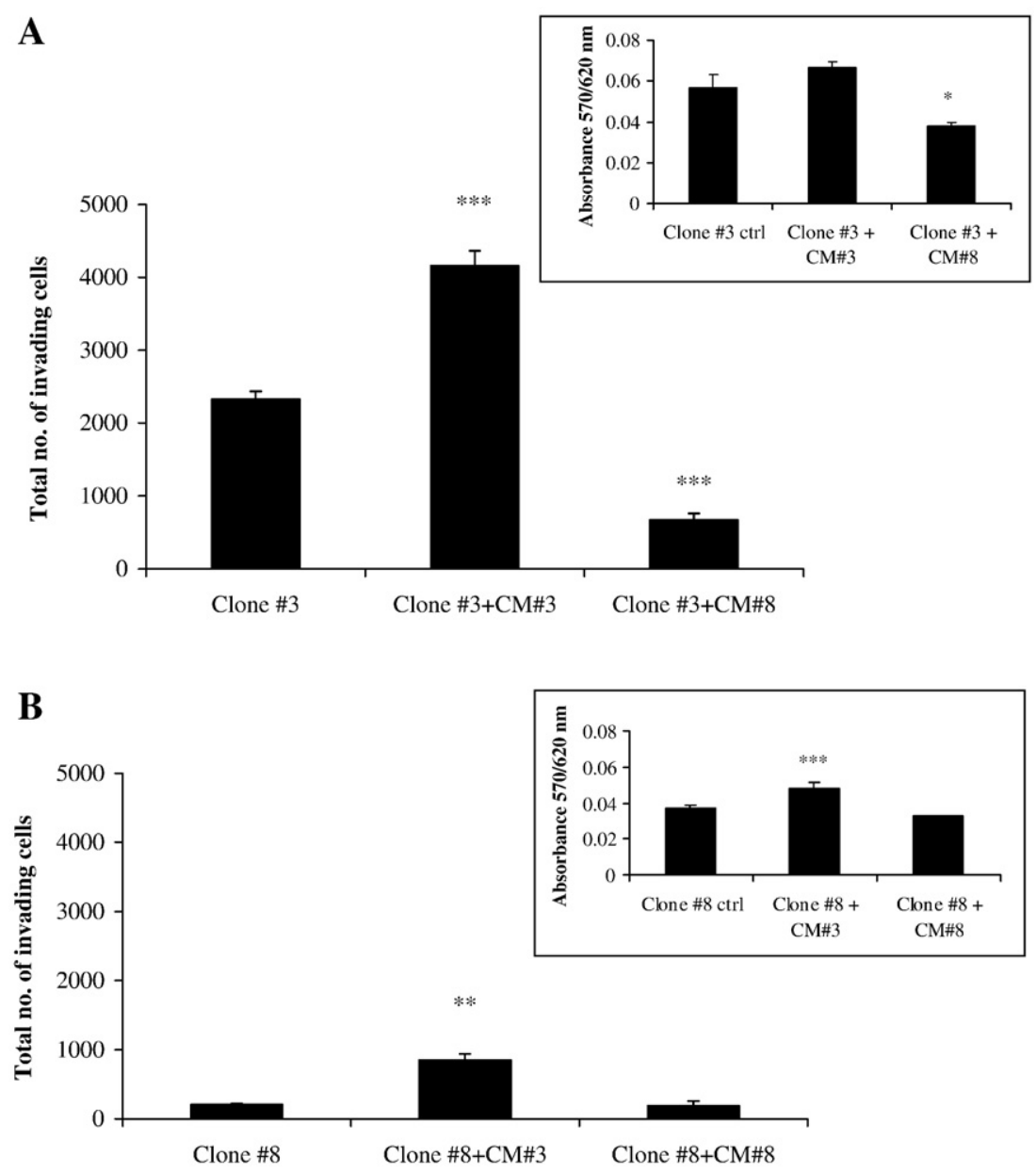

Fig. 1-A. Invasion assays of Clone \#3 under control conditions and containing CM\#3 and CM\#8 in the invasion insert. B. Invasion assays of Clone \#8 under control conditions and containing CM\#3 and CM\#8 in the invasion insert. The total number of invading cells was determined by counting the number of cells per field in 10 random fields, at 200x magnification. The average number of cells per field was then multiplied by a factor of 140 (growth area of membrane/field area viewed at 200x magnification (calibrated using a microscope graticule)). Insert: Colorimetric relative quantification of invading cells was also determined by elution of inserts with $0.33 \%$ acetic acid and spectrophotometrically quantified. All experiments were performed in triplicate. Statistics; ${ }^{*} p \leq 0.05,{ }^{* *} p \leq 0.01,{ }^{* * *} p \leq 0.005$ Student's t-test. 


\subsection{Collection of pancreatic cancer cell line-conditioned media}

Clone \#3 and Clone \#8 monolayers were cultured in T175 cm 3 flasks until approximately $60 \%$ confluent in culture medium. Cells were then washed $3 \times$ with serum free (SF) DMEM and incubated for $1 \mathrm{~h}$ with SF DMEM. Cells were washed $3 \times$ again in SF DMEM, then placed in SF DMEM for $72 \mathrm{~h}$. At the time of collection, cellular debris was removed by centrifugation and filtration through a $0.22 \mu \mathrm{m}$ filter; aliquots were frozen at $-80{ }^{\circ} \mathrm{C}$ until analysed.

\subsection{Invasion assays}

Invasion assays were performed using an adapted method [10]. Matrigel was diluted to $1 \mathrm{mg} / \mathrm{ml}$ in serum free DMEM. $100 \mu \mathrm{l}$ of matrigel was placed into each insert (Falcon) $(8.0 \mu \mathrm{m}$ pore size) in a 24-well plate (Costar). The coated inserts were incubated overnight at $4{ }^{\circ} \mathrm{C}$. The following day, the matrigel was allowed to polymerise at $37^{\circ} \mathrm{C}$ for $1 \mathrm{~h}$. The inserts were then washed with DMEM, $100 \mu \mathrm{l}$ of $1 \times 10^{5} / 100 \mu \mathrm{l}$ cells in complete DMEM and $100 \mu \mathrm{l}$ of CM supplemented with $5 \%$ serum was added onto the insert. $250 \mu \mathrm{l}$ of total DMEM:250 $\mu \mathrm{l} \mathrm{CM}$ supplemented with $5 \%$ serum was added to the 24 -well plate. After $24 \mathrm{~h}$ incubation, the inside of the insert was wiped with a wet cotton swab. The under surface was gently rinsed with PBS and stained with $0.25 \%$ crystal violet for $10 \mathrm{~min}$, rinsed again with sterile water and allowed to dry. To determine the total number of invading cells, the inserts were then viewed under the microscope and the number of cells per field in 10 random fields, were counted at 200x magnification. The average number of cells per field was then multiplied by a factor of 140 (growth area of membrane/field area viewed at 200x magnification (calibrated using a microscope graticule)). Colorimetric quantification of invasion was determined by eluting the crystal violet stain solution with $33 \%$ acetic acid extraction buffer and the absorbance was read with a Bio-Tek plate reader (Becton Dickinson Labware) at $570 \mathrm{~nm}$ and a reference wavelength of $620 \mathrm{~nm}$. The mean values were obtained from a minimum of three individual experiments and were subjected to t-tests. All experiments were performed in triplicate.

\subsection{Sample preparation and protein labelling}

Six individual $50 \mathrm{ml}$ samples for both CM\#3 and CM\#6 (biological replicates and technical replicates/CM of cell line) were concentrated using a 10,000 molecular weight cut-off (Millipore); samples were cleaned-up using a ready-prep 2D clean-up kit (Bio-Rad). Protein concentration was determined using the BCA protein assay kit (Bio-Rad). CM samples were labelled with $\mathrm{N}$-hydroxy succinimidyl ester-derivatives of the cyanine dyes Cy2, Cy3 and Cy5 [11]. Typically, $50 \mu \mathrm{g}$ of the CM was minimally labelled with 200 pmol of either Cy3 or Cy5 for comparison on the same 2-D gel. Labelling reactions were performed on ice in the dark for $30 \mathrm{~min}$ and then quenched with a 50-fold molar excess of free lysine to dye for $10 \mathrm{~min}$ on ice. A pool containing equal amounts of all samples was also prepared and labelled with Cy2 to be used as a standard on all gels to aid image matching and cross-gel statistical analysis. The Cy3 and Cy5 reverse labelling reactions (50 $\mu$ g of each) from each CM sample were mixed and run on the same gels with an equal amount $(50 \mu \mathrm{g})$ of Cy2-labelled standard.

\subsection{Protein separation by 2-DE and gel imaging}

Immobilised $24 \mathrm{~cm}$ linear pH gradient (IPG) strips, pH 3-11, were rehydrated in rehydration buffer (7 M urea, $2 \mathrm{M}$ thiourea, $4 \%$ CHAPS, $0.5 \%$ IPG buffer, $50 \mathrm{mM} \mathrm{DTT}$ ) overnight, according to manufacturer guidelines. IEF was performed using an IPGphor apparatus (GE Healthcare) for $40 \mathrm{kV} / \mathrm{h}$ at $20^{\circ} \mathrm{C}$ with resistance set at $50 \mathrm{~mA}$. Strips were equilibrated for $20 \mathrm{~min}$ in $50 \mathrm{mM}$ TrisHCL, pH 8.8, $6 \mathrm{M}$ urea, 30\% v/v glycerol, 1\% w/v SDS containing $65 \mathrm{mM}$ DTT and then for $20 \mathrm{~min}$ in the same buffer containing $240 \mathrm{mM}$ iodoacetamide. Equilibrated IPG strips were transferred onto $18 \times 20 \mathrm{~cm} 12.5 \%$ uniform polyacrylamide gels poured between low fluorescence glass plates. Strips were overlaid with $0.5 \% \mathrm{w} / \mathrm{v}$ low melting point agarose in running buffer containing bromophenol blue. Gels were run at $2.5 \mathrm{~W} / \mathrm{gel}$ for $30 \mathrm{~min}$ and then $100 \mathrm{~W}$ total at $10^{\circ} \mathrm{C}$. All the images were collected on a Typhoon 9400 Variable Mode Imager (GE Healthcare). Statistics and quantification of protein expression were carried out in DeCyder software (GE Healthcare).

\subsection{Spot digestion and MALDI-TOF analysis}

Excision of protein spots, trypsin digestion and protein identification by MS analysis using an Ettan MALDI-TOF Pro (GE Healthcare) were performed. Preparative gels containing $300 \mu \mathrm{g}$ of protein were fixed in $30 \% \mathrm{v} / \mathrm{v}$ methanol, $7.5 \% \mathrm{v} / \mathrm{v}$ acetic acid overnight and washed in water, and total protein was detected by post-staining with $\mathrm{CBB}$ and Deep purple stain (Molecular Probes) for $3 \mathrm{~h}$ at room temperature. Excess dye was removed by washing twice in water, and gels were imaged using a Typhoon 9400 Variable Mode Imager (GE Healthcare) at

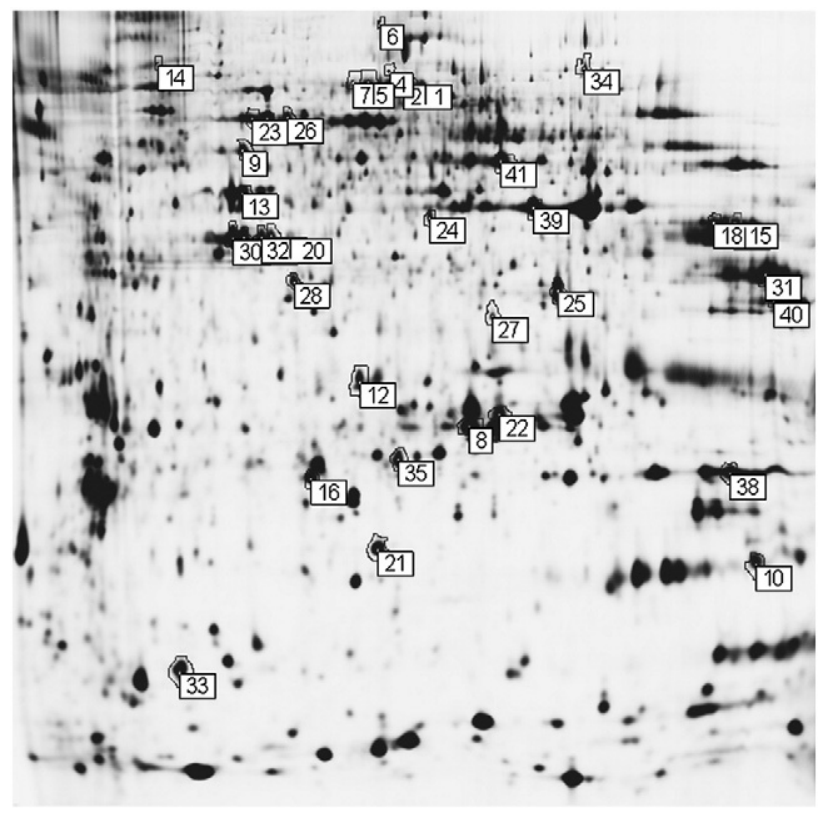

Fig. 2-Protein expression map (PEM) of differentially regulated proteins in the comparison of $\mathrm{CM} \# 3$ versus $\mathrm{CM} \# 8$. All protein numbers correspond to Tables 1 and 2. 
the appropriate excitation and emission wavelengths for the stain. The subsequent gel image was imported into the BVA module of DeCyder software and was matched to images generated from DIGE analysis. Spots of interest were selected and confirmed using this software for subsequent picking using an Ettan Spot Picker. Gel plugs were placed into a presiliconised $1.5 \mathrm{ml}$ plastic tube for destaining, desalting and washing steps. The remaining liquid above the gel plugs was removed and sufficient $\mathrm{ACN}$ was added in order to cover the gel plugs. Following shrinkage of the gel plugs, ACN was removed and the protein containing gel pieces were rehydrated for 5 min with a minimal volume of $100 \mathrm{mM}$ ammonium bicarbonate. An equal volume of ACN was added, and after $15 \mathrm{~min}$ of incubation the solution was removed from the gel plugs and the samples were dried for 30 min using a vacuum centrifuge. Individual gel pieces were then rehydrated in digestion buffer (12.5 ng trypsin per $\mu \mathrm{l}$ of $10 \%$ ACN, $40 \mathrm{mM}$ ammonium bicarbonate) to cover the gel pieces. Exhaustive digestion was carried out overnight at $37{ }^{\circ} \mathrm{C}$. After digestion, the samples were centrifuged at $12,000 \times g$ for $10 \mathrm{~min}$ using a bench top centrifuge. The supernatant was carefully removed from each sample and placed into clean plastic tubes. Samples were stored at $-80^{\circ} \mathrm{C}$ until analysed by M.S. For spectrometric analysis, mixtures of tryptic peptides from individual samples were desalted using Millipore C-18 Zip-Tips (Millipore) and eluted onto the sample plate with the matrix solution $(5 \mathrm{mg} / \mathrm{ml} \mathrm{CHCA}$ in $50 \%$ ACN/ $0.1 \%$ TFA v/v). Mass spectra were recorded using the MALDI-

Table 1 - 2D DIGE and MALDI-TOF MS identification of down-regulated proteins in the conditioned media of the invasive Clone \#3

\begin{tabular}{|c|c|c|c|c|c|c|c|}
\hline No. & Protein name & $\begin{array}{l}\text { Gene } \\
\text { symbol }\end{array}$ & $\begin{array}{l}\text { Protein AC } \\
\text { number }\end{array}$ & $\begin{array}{l}\text { Theoretical } \\
\text { pI/Mw }\end{array}$ & $\begin{array}{c}\% \\
\text { Coverage }\end{array}$ & $\begin{array}{l}\text { Fold } \\
\text { change }\end{array}$ & Molecular function \\
\hline 1 & Gelsolin isoform b (a) & GSN & gi|38044288| & $5.6 / 80.9$ & 17.9 & $-21.0^{* * *}$ & $\begin{array}{l}\text { Structural constituent of the } \\
\text { cytoskeleton }\end{array}$ \\
\hline 2 & Gelsolin isoform b (b) & GSN & gi|38044288| & $5.6 / 80.9$ & 24.4 & $-15.2^{* * *}$ & $\begin{array}{l}\text { Structural constituent of the } \\
\text { cytoskeleton }\end{array}$ \\
\hline 3 & Gelsolin isoform b (c) & GSN & gi|38044288| & $5.6 / 80.9$ & 18.6 & $-10.7^{* * *}$ & $\begin{array}{l}\text { Structural constituent of the } \\
\text { cytoskeleton }\end{array}$ \\
\hline 4 & Gelsolin isoform b (f) & GSN & gi|38044288| & $5.6 / 80.9$ & 15.2 & $-6.4^{* * *}$ & $\begin{array}{l}\text { Structural constituent of the } \\
\text { cytoskeleton }\end{array}$ \\
\hline 5 & Gelsolin isoform b (d) & GSN & gi|38044288| & $5.6 / 80.9$ & 18.3 & $-3.8^{* * *}$ & $\begin{array}{l}\text { Structural constituent of the } \\
\text { cytoskeleton }\end{array}$ \\
\hline 6 & Gelsolin isoform b (g) & GSN & gi|38044288| & $5.6 / 80.9$ & 18.5 & $-3.4^{* * *}$ & $\begin{array}{l}\text { Structural constituent of the } \\
\text { cytoskeleton }\end{array}$ \\
\hline 7 & Gelsolin (amyloidosis: Finnish type) & GSN & gi|55960299| & $5.9 / 86.0$ & 9.5 & $-2.5^{* * *}$ & $\begin{array}{l}\text { Structural constituent of the } \\
\text { cytoskeleton }\end{array}$ \\
\hline 8 & Pro-MMP-2TIMP2 complex & TIMP2 & gi|22218678| & $6.5 / 22.4$ & 30.9 & $-1.8^{* * *}$ & ECM structural constituent \\
\hline 9 & Beta actin (a) & АСTB & gi|15277503| & $5.6 / 40.5$ & 36.6 & $-1.7^{* * *}$ & $\begin{array}{l}\text { Structural constituent of the } \\
\text { cytoskeleton }\end{array}$ \\
\hline 10 & $\begin{array}{l}\text { Nucleoside-diphosphate kinase } 2 \\
\text { isoform }\end{array}$ & NDPK2 & gi|66392203| & $9.3 / 30.5$ & 21.7 & $-1.7^{* *}$ & Transcription factor activity \\
\hline 11 & Beta actin (c) & ACTB & gi|15277503| & $5.6 / 40.5$ & 24.4 & $-1.6^{* * *}$ & $\begin{array}{l}\text { Structural constituent of the } \\
\text { cytoskeleton }\end{array}$ \\
\hline 12 & Proteasome activator reg (alpha) & PSME1 & gi|2780883| & $7.1 / 16.3$ & 44.3 & $-1.5^{* * *}$ & $\begin{array}{l}\text { Ubiquitin-specific protease } \\
\text { activity }\end{array}$ \\
\hline 13 & Beta actin (b) & ACTB & gi|15277503| & $5.6 / 40.5$ & 24.2 & $-1.5^{* * *}$ & $\begin{array}{l}\text { Structural constituent of the } \\
\text { cytoskeleton }\end{array}$ \\
\hline 14 & $\begin{array}{l}\text { Heat shock protein 90-alpha } \\
\text { (HSP86) }\end{array}$ & HSP86 & gi|92090606| & $4.9 / 85.0$ & 24.5 & $-1.5^{* * *}$ & Chaperone activity \\
\hline 15 & Phosphoglycerate kinase 1 (a) & PGK1 & gi|48145549| & $8.6 / 44.9$ & 25.7 & $-1.4^{* * *}$ & Catalytic activity \\
\hline 16 & Thioredoxin peroxidase & PRDX2 & gi|9955016| & $5.7 / 21.6$ & 28.4 & $-1.4^{* * *}$ & Peroxidase activity \\
\hline 17 & Phosphoglycerate kinase 1 (b) & PGK1 & gi|48145549| & $8.6 / 44.9$ & 25.7 & $-1.4^{* * *}$ & Catalytic activity \\
\hline 18 & Phosphoglycerate kinase 1 (c) & PGK1 & gi|48145549| & $8.6 / 44.9$ & 27.3 & $-1.4^{* * *}$ & Catalytic activity \\
\hline 19 & $\begin{array}{l}\text { Heat shock } 70 \mathrm{kDa} \text { protein } 8 \\
\text { isoform } 2(\mathrm{~b})\end{array}$ & HSPA8 & gi|62896815| & $5.6 / 53.6$ & 16.8 & $-1.3^{* * *}$ & Heat shock protein activity \\
\hline 20 & Beta $\operatorname{actin}(\mathrm{d})$ & ACTB & gi|15277503| & $5.6 / 40.5$ & 27.3 & $-1.3^{* * *}$ & $\begin{array}{l}\text { Structural constituent of the } \\
\text { cytoskeleton }\end{array}$ \\
\hline 21 & NM23-H1 & NME1 & gi|29468184| & $5.4 / 19.8$ & 27.1 & $-1.3^{* * *}$ & Catalytic activity \\
\hline 22 & Triosephosphate isomerase & TPI1 & gi|999893| & $6.5 / 26.8$ & 29.0 & $-1.3^{* * *}$ & Isomerase activity \\
\hline 23 & $\begin{array}{l}\text { Heat shock } 70 \mathrm{kDa} \text { protein } 8 \\
\text { isoform } 2 \text { (a) }\end{array}$ & HSPA8 & gi|62896815| & $5.6 / 53.6$ & 28.8 & $-1.3^{* * *}$ & Heat shock protein activity \\
\hline 24 & $\begin{array}{l}\text { S-adenosylhomocysteine } \\
\text { hydrolase }\end{array}$ & AHCY & gi|178277| & $6.0 / 48.2$ & 10.6 & $-1.3^{* * *}$ & Hydrolase activity \\
\hline 25 & Malate dehydrogenase cytosolic & MDH1 & gi|7431153| & $5.9 / 36.6$ & 20.1 & $-1.2^{* * *}$ & Catalytic activity \\
\hline 26 & $\begin{array}{l}\text { Heat shock } 70 \mathrm{kDa} \text { protein } 8 \\
\text { isoform } 2 \text { variant (c) }\end{array}$ & HSPA8 & gi|62896815| & $5.6 / 53.6$ & 19.7 & $-1.2^{* * *}$ & Heat shock protein activity \\
\hline 27 & Nucleoside phosphorylase & NP & 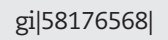 & $6.5 / 32.2$ & 36.1 & $-1.2^{* * *}$ & Phosphorylase activity \\
\hline
\end{tabular}


Table 2 - 2D DIGE and MALDI-TOF MS identification of up-regulated proteins in the conditioned media of the invasive Clone \#3

\begin{tabular}{|c|c|c|c|c|c|c|c|}
\hline No. & Protein name & $\begin{array}{l}\text { Gene } \\
\text { symbol }\end{array}$ & $\begin{array}{l}\text { Protein AC } \\
\text { number }\end{array}$ & $\begin{array}{l}\text { Theoretical } \\
\text { pI/Mw }\end{array}$ & $\begin{array}{c}\% \\
\text { Coverage }\end{array}$ & $\begin{array}{l}\text { Fold } \\
\text { change }\end{array}$ & Molecular function \\
\hline 28 & $\begin{array}{l}\text { Capping protein, muscle } \mathrm{Z} \text { line, } \\
\text { alpha } 1\end{array}$ & CAPZA1 & gi|12652789| & $5.4 / 33.0$ & 39.9 & $1.2^{* * *}$ & Structural molecule activity \\
\hline 29 & Beta actin $(g)$ & АСТВ & gi|15277503| & $5.6 / 40.5$ & 30.6 & $1.2^{*}$ & $\begin{array}{l}\text { Structural constituent of the } \\
\text { cytoskeleton }\end{array}$ \\
\hline 30 & Beta actin (f) & ACTB & gi|15277503| & $5.6 / 40.5$ & 24.4 & $1.2^{*}$ & $\begin{array}{l}\text { Structural constituent of the } \\
\text { cytoskeleton }\end{array}$ \\
\hline 31 & $\begin{array}{l}\text { Glycerate-3-phosphate } \\
\text { dehydrogenase }\end{array}$ & GAPDH & gi|31645| & $8.4 / 36.2$ & 19.4 & $1.2^{* *}$ & Catalytic activity \\
\hline 32 & Beta actin (e) & ACTB & gi|15277503| & $5.6 / 40.5$ & 24.5 & $1.2^{*}$ & $\begin{array}{l}\text { Structural constituent of the } \\
\text { cytoskeleton }\end{array}$ \\
\hline 33 & Galectin-1 & LGALS1 & gi|56554350| & $5.1 / 14.8$ & 38.1 & $1.3^{* * *}$ & Receptor binding \\
\hline 34 & $\mathrm{Mu}$-protocadherin isoform & MUCDHL & gi|62020550| & $4.8 / 88.4$ & 18.2 & $1.3^{* * *}$ & $\begin{array}{l}\text { Cell adhesion molecule } \\
\text { activity }\end{array}$ \\
\hline 35 & Pi glutathione transferase & GSTP1 & gi|34811304| & $5.7 / 23.4$ & 36.4 & $1.3^{* * *}$ & $\begin{array}{l}\text { Glutathione transferase } \\
\text { activity }\end{array}$ \\
\hline 36 & Elongation factor & EEF1A1 & gi|15277711| & $9.3 / 46.5$ & 12.1 & $1.4^{* * *}$ & $\begin{array}{l}\text { Translation regulator } \\
\text { activity }\end{array}$ \\
\hline 37 & Alpha enolase (b) & ENO1 & gi|2661039| & 7.0/47.4 & 28.6 & $1.5^{* * *}$ & Catalytic activity \\
\hline 38 & Peroxiredoxin 1 & PRDX1 & gi|55959887| & $6.4 / 19.1$ & 53.2 & $1.5^{* * *}$ & Peroxidase activity \\
\hline 39 & Alpha enolase (a) & ENO1 & gi|2661039| & 7.0/47.4 & 15.5 & $1.5^{* * *}$ & Catalytic activity \\
\hline 40 & $\begin{array}{l}\text { Mitochondrial malate } \\
\text { dehydrogenase }\end{array}$ & $\mathrm{MDH} 2$ & gi|12804929| & $9.4 / 35.9$ & 37.0 & $1.6^{* * *}$ & Catalytic activity \\
\hline 41 & Aldehyde dehydrogenase $1 \mathrm{~A} 1$ & ALDH1A1 & gi|2183299| & $6.3 / 55.4$ & 18.4 & $21.0^{* * *}$ & $\begin{array}{l}\text { Aldehyde dehydrogenase } \\
\text { activity }\end{array}$ \\
\hline
\end{tabular}

The theoretical isoelectric point (pI) and molecular weight (Mw) were calculated from the sequence of the protein in the database. Isoforms of the same protein are referred to as (a), (b) etc. The percentage coverage is the amount of the protein sequence covered by the matched peptides. Statistical analysis between replicates is referred to as; ${ }^{*} p \leq 0.05,{ }^{* * *} p \leq 0.01,{ }^{* * *} p \leq 0.005$.

TOF instrument operating in the positive reflectron mode at the following parameters: accelerating voltage $20 \mathrm{kV}$; and pulsed extraction; on (focus mass 2500). Internal calibration was performed using anti-analysis peaks at $\mathrm{m} / \mathrm{z} 842.50, \mathrm{~m} / \mathrm{z}$ 2211.104 and external calibration was performed using Pep4 mix. The mass spectra were analysed using MALDI evaluation software (GE Healthcare), and protein identification was achieved with the PMF Pro-Found search engine.

\subsection{Western blot}

Protein concentrations were determined using the Bio-Rad protein assay (Bio-Rad). $35 \mu$ g of protein was separated by $7.5 \%$ SDS-PAGE under reducing conditions. Proteins were transferred to nitrocellulose membrane. Membranes were blocked at $4{ }^{\circ} \mathrm{C}$ overnight in TBS $(25 \mathrm{mM}$ Tris- $\mathrm{HCl}, \mathrm{pH} 7.4,150 \mathrm{mM} \mathrm{NaCl}$, $2.7 \mathrm{mM} \mathrm{KCl}$ ) containing $5 \%(\mathrm{w} / \mathrm{v})$ lowfat milk powder. Membranes were probed with monoclonal antibodies, antigelsolin (G4896, Sigma) and anti-aldehyde dehydrogenase 1A1 (488-501, Calbiochem). Membranes were washed $3 \times$ for 5 min with PBS-Tween-20 (0.5\%) and incubated with secondary antibodies, anti-mouse and anti-goat obtained from Sigma for $1 \mathrm{~h}$ at RT and washing step was repeated. Detection was performed with Luminol reagent (Santa Cruz Biotechnology).

\subsection{SiRNA transfection}

For each set of siRNA transfections carried out, a non-treated control and a scrambled (SCR) transfection control (Ambion, \# 17010) were used. SiRNA experiments were set up using $2 \mu 1$ NeoFx (Ambion, AM4511), to transfect $30 \mathrm{nM}$ siRNA at a cell density of $3 \times 10^{5} /$ well $/ \mathrm{ml}$ of a 6 -well plate. Cells were transfected with two different GSN siRNAs, both of which target variant 1 , isoform a and variant 2, isoform b of GSN (NM_000177 Exon 5, NM_198252 Exon 6: Sequence GCAAUCGGUAUGAAAGACUtt (sense), Ambion, \#8127) and (NM_000177 Exon 2, NM_198252 Exon 3: Sequence GCUGAGGAACGGAAAUCUGtt (sense), Ambion, \#8031) and with three different ALDH1A1 siRNAs targeting the ALDH1A1 isoform (NM_000689 Exon 11, 12: Sequence GGAACAGUGUGGGUGAAUUtt (sense), Ambion, \#106197), (NM_000689 Exon 9:

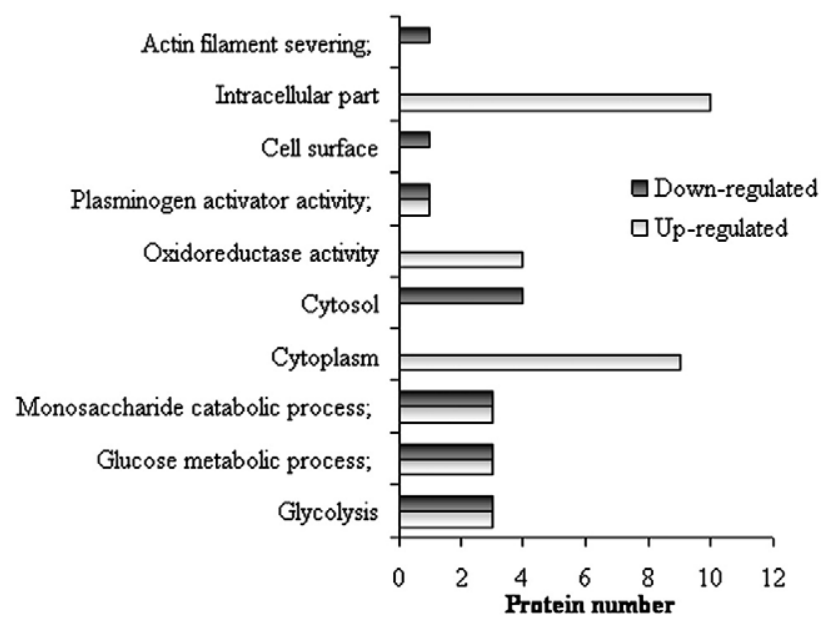

Fig. 3-Term-ranking GO categories. Representation of the 10 top-ranked functional categories, using GO terms that are enriched in all significantly differentially expressed proteins identified between CM\#3 and CM\#8. 
Sequence GGAGUGUUGAGCGGGCUAAtt (sense), Ambion, \#106196), and (NM_000689 Exon 4: Sequence GGGCCGUACAAUACCAAUUtt (sense), Ambion, \#106195). After $32 \mathrm{~h}$, the media were removed, washed $3 \times$ in SF DMEM and $1 \mathrm{ml}$ of SF DMEM was added onto the cells. The effects of siRNA silencing were analysed on the SF CM after 48 and $72 \mathrm{~h}$. SiRNA transfected SF CM was collected, centrifuged and filtered through a $0.22 \mu \mathrm{m}$ filter. SiRNA transfected SF CM was concentrated using 10,000 molecular weight cut-off concentrators (Millipore); samples were cleaned-up using a readyprep 2D clean-up kit (Bio-Rad) and protein concentration was determined using the BCA protein assay kit (Bio-Rad). Western blot analysis was then carried out to assess efficient transfection. All experiments were repeated in triplicate.

\subsection{Statistical analysis}

Student's t-test was used to identify the difference in mean values between treated and non-treated samples. In siRNA experiments, siRNA scrambled transfected cells were used as control compared to siRNA treated samples. This was to ensure no 'off-target' effects of the transfection procedure. Non-treated controls were used to ensure scrambled siRNA was having no effects and to normalise data. A $p$ value of $\leq 0.05^{*}$ was deemed significant, $p$ value $\leq 0.01^{* *}$ was deemed more significant, and $p$ value $\leq 0.005^{* * *}$ was deemed highly significant.

\section{Results}

3.1. Factors in conditioned medium alter invasive abilities of pancreatic cancer cell lines

CM\#3 enhanced invasion of Clone \#3 by 1.8 -fold $(p=0.0008)$ compared to an invasion assay control containing fresh medium. Clone \#3 containing $\mathrm{CM} \# 8$ in the invasion assay showed a 3.33-fold decrease in invasion $(p<0.001)$ (Fig. 1A). Fig. $1 \mathrm{~B}$ shows that $\mathrm{CM} \# 3$ significantly increased the invasion (4.2-fold $(p=0.005)$ ) of Clone \#8 compared to an invasion assay control containing fresh medium. CM\#8 caused a very slight (1.1-fold) decrease in invasion of Clone \#8 ( $p=0.7)$.

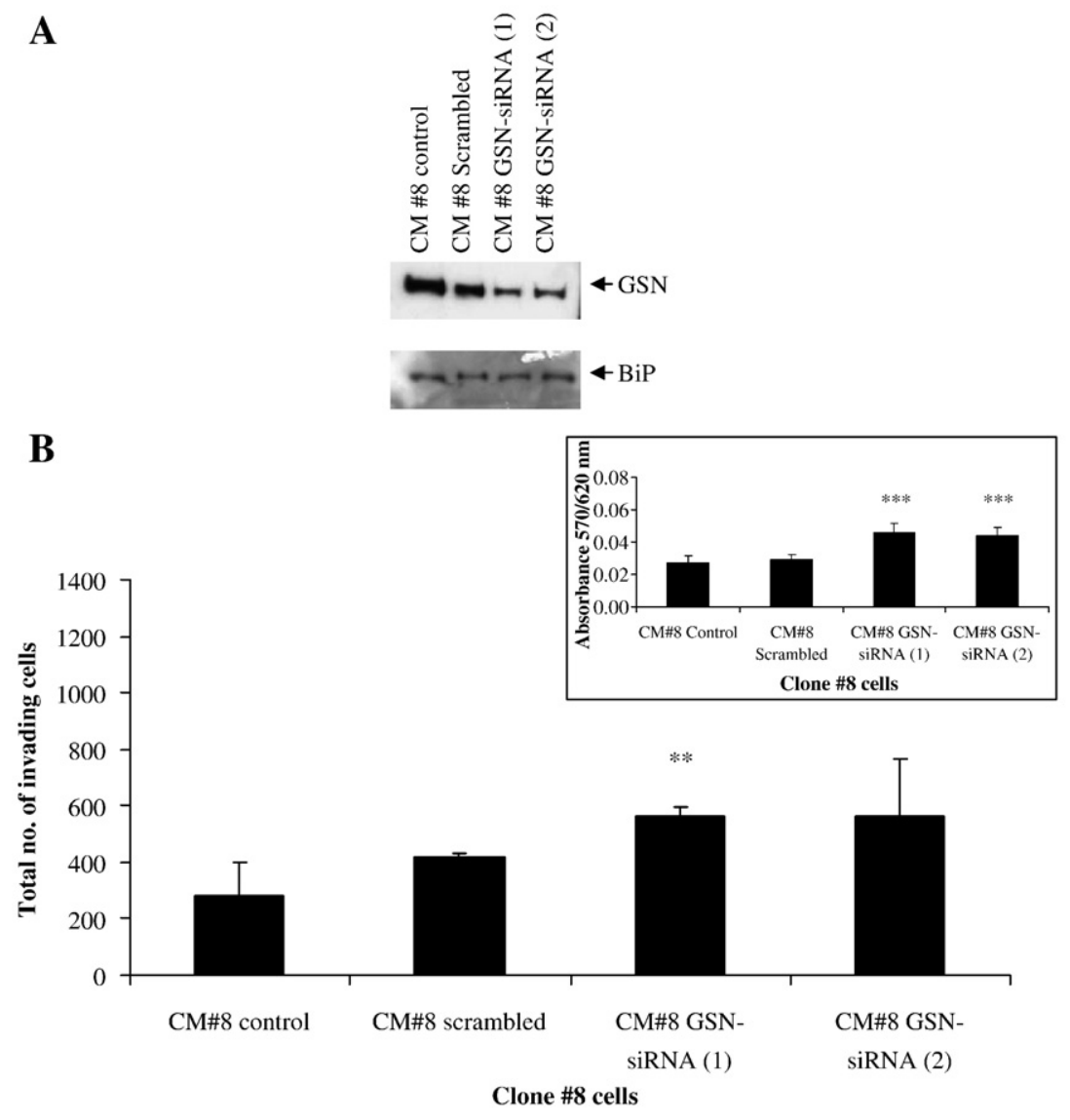

Fig. 4-A. Western blot of two independent target siRNA-GSN knockdowns in CM\#8. Bip antibody was used to demonstrate even loading between the samples. B. Invasion assay of Clone \#8 cells with the addition of CM\#8 untreated control, CM\#8 scrambled siRNA, CM\#8 treated with GSN-siRNA (1) and CM\#8 treated with GSN-siRNA (2) $(n=3)$. The total number of invading cells was determined by counting the number of cells per field in 10 random fields, at $200 \times$ magnification. The average number of cells per field was then multiplied by a factor of 140 (growth area of membrane/field area viewed at 200x magnification (calibrated using a microscope graticule)). Insert: Colorimetric relative quantification of invading cells was also determined by elution of inserts with $0.33 \%$ acetic acid and spectrophotometrically quantified. Experiments performed in triplicate. Statistics; ${ }^{*} p \leq 0.05,{ }^{* *} p \leq 0.01$, ${ }^{* * *} p \leq 0.005$. 
3.2. Proteomic analysis of CM\#3 and CM\#8 by 2-D DIGE MALDI-TOF MS

Proteins found in CM\#3 and CM\#8 were analysed by 2-D DIGE. Triplicate biological repeats were reverse labelled with Cy3 and Cy5 dyes. All samples used in the experiment were pooled and labelled with the internal dye, Cy2. Each sample was compared internally to the same standard, to account for any gel-to-gel variation. DeCyder image analysis merged the Cy2, Cy3 and Cy5 images for each gel and detected spot boundaries for the calculation of normalised protein abundance. All paired images were then matched to generate comparative cross-gel statistical analysis. Biological variation analysis of these spots showing greater than 1.2-fold change in expression with a t-test score of $<0.05$, revealed 41 proteins significantly differentially regulated between CM\#3 versus CM\#8. Protein expression maps (PEM) of all identified proteins are shown in Fig. 2 (position number corresponds to
Tables 1 and 2). For protein identification, all proteins were digested and identified at least twice from separate gels with MALDI-TOF MS. An expectation value of $<0.002$ was used for all reported identifications, which indicates a $0.2 \%$ chance that the identification is random. Table 1 outlines the down-regulated proteins in CM\#3 compared to CM\#8 and Table 2 shows the proteins up-regulated in CM\#3 compared to $\mathrm{CM} \# 8$.

\subsection{Gene ontology enrichment analysis}

Using DAVID gene ID tool software (http://david.abcc.ncifcrf. gov), all the proteins differentially regulated in our model were converted to their gene IDs. Gene ontology (GO STAT) (http://gostat.wehi.edu.au/cgi-bin/goStat.pl) was then used to classify the proteins and their corresponding genes into gene categories. Enrichment of a particular ontology term, for significantly expressed genes in response to the process

A
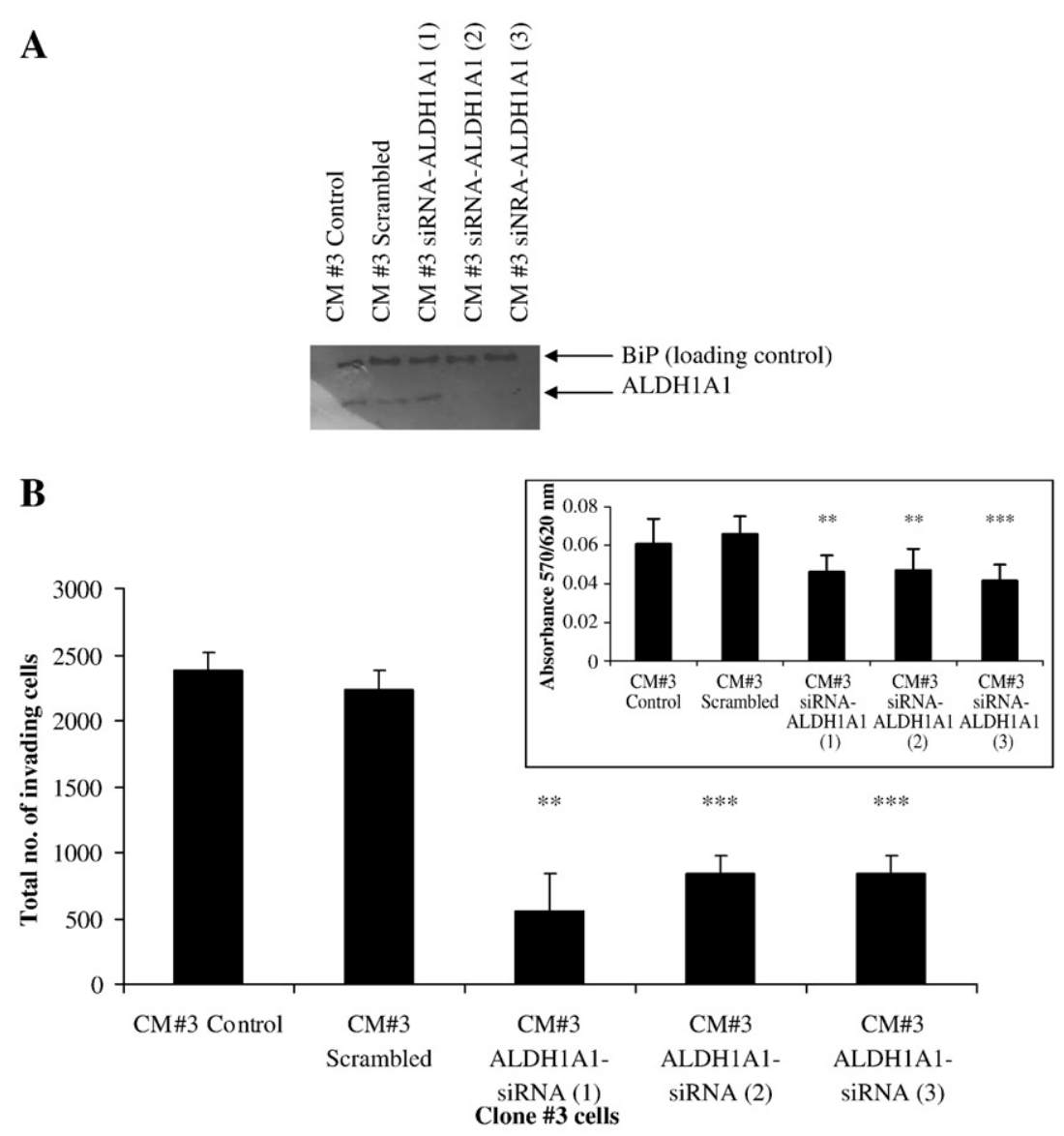

Fig. 5-A. Western blot of ALDH1A1 knockdown in CM\#3 untreated control, scrambled, siRNA ALDH1A1 (1), siRNA ALDH1A1 (2) and siRNA ALDH1A1 (3). B. Invasion assay of Clone \#3 with addition of CM\#3 media (control), CM\#3 media with scrambled siRNA, CM\#3 treated with ALDH1A1 siRNA (1), CM\#3 treated with ALDH1A1 siRNA (2), CM\#3 treated with ALDH1A1 siRNA (3) $(n=3)$. The total number of invading cells was determined by counting the number of cells per field in 10 random fields, at $200 \times$ magnification. The average number of cells per field was then multiplied by a factor of 140 (growth area of membrane/field area viewed at $200 \times$ magnification (calibrated using a microscope graticule)). Insert: Colorimetric relative quantification of invading cells was also determine by elution of inserts with $0.33 \%$ acetic acid and spectrophotometrically quantified. The total number of invading cells were stained with $0.25 \%$ crystal violet, eluted with $0.33 \%$ acetic acid and spectrophotometrically quantified, to determine the relative number of invading cells. Experiments performed in triplicate. Magnification, 200x. Scale bar, $200 \mu \mathrm{m}$. Statistics; ${ }^{*} p \leq 0.05,{ }^{* *} p \leq 0.01,{ }^{* * *} p \leq 0.005$. 
under study, means that the ontology term is likely to be involved in the process. In our study, the process refers to factors involved in invasion of pancreatic cancer. Using the over-expression function of the software and false discovery rate (Benjamini) statistics, $30 \mathrm{GO}$ terms were found significantly enriched in both the up-regulated and down-regulated proteins list in CM\#3 versus CM\#8. The "glycolysis" term achieved the highest degree of significance in both the up-regulated and down-regulated gene class $(p=0.005$, $p=0.001)$. In the up-regulated class, "cytoplasm" $(p=0.01)$, "oxidoreductase activity" ( $p=0.01)$ and "intracellular part"(including cytoplasmic and nucleus proteins) $(p=0.03)$ were highly significant terms. In the down-regulated class, "cytosol"-(no membranous or subcellular components) $(p=0.007)$, and "actin filament severing" $(p=0.03)$ were also significantly enhanced. Fig. 3 outlines the top ten ranked functional categories using GO terms in the differentially expressed proteins in the pancreatic cancer model.

\subsection{Invasion inhibitory role of GSN by siRNA in CM\#8}

GSN, a down-regulated protein in CM\#3 compared to CM\#8 was analysed to assess its functional involvement in pancreatic cancer cell invasion. Fig. 4A shows the successful knockdown of GSN in CM\#8 by two independent siRNA targets relative to control (untreated) and siRNA scrambled CM\#8. The addition of CM from Clone \#8 GSN-siRNA (1) onto Clone \#8 cells significantly increased the invasive abilities of the cells by 1.3 fold $(p=0.01)$. CM from GSN-siRNA (2) treated Clone \#8 cells onto Clone \#8 also increased the invasiveness of the cells 1.5 fold ( $p=0.2)$ (Fig. 4B).

3.5. Invasion enhancement role of ALDH1A1 by siRNA in
CM\#3

ALDH1A1, which is up-regulated in CM\#3 compared to CM\#8, was knocked down in Clone \#3 to assess its functional role in pancreatic cancer cell invasion. Fig. 5A shows the efficient knock down of ALDH1A1 in CM\#3 by three independent siRNAs. CM from ALDH1A1-siRNA treated Clone \#3 cells was added into the invasion assay of Clone \#3. Reduction of ALDH1A1 expression resulted in a significant decrease in invasion of Clone \#3. CM\#3 ALDH1A1-siRNA (1) on Clone \#3 reduced invasion 4.2-fold ( $p=0.01)$, ALDH1A1 siRNA (2) decreased invasion 2.7-fold $(p=0.003)$ and ALDH1A1 siRNA (3) also significantly reduced the invasive abilities of Clone \#3 2.5fold ( $p=0.02)$, compared to the scrambled control (Fig. 5B).

A
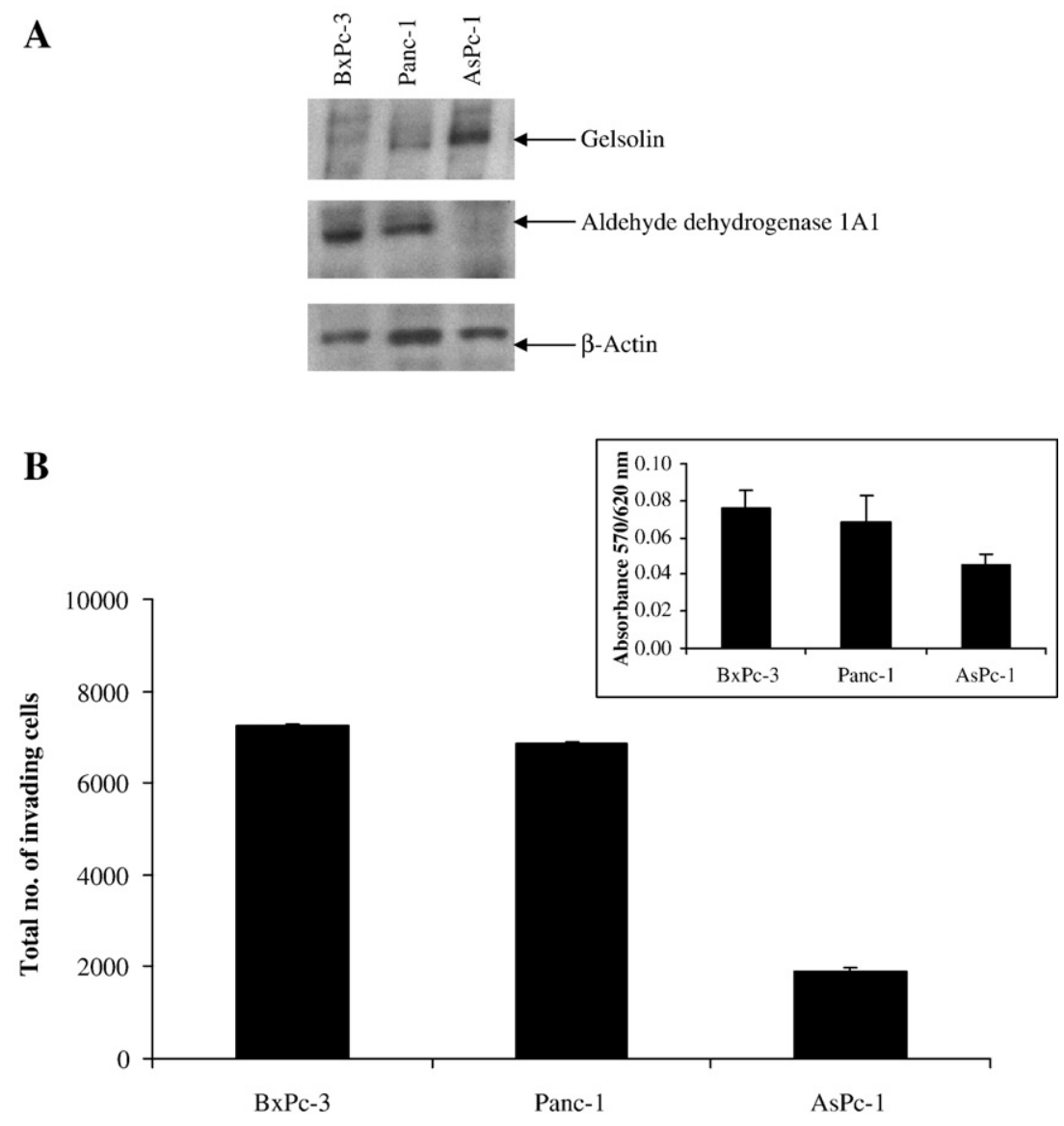

Fig. 6-A. Western blot of GSN and ALDH1A1 expression in pancreatic cancer cell lines, BxPc-3, Panc-1 and AsPc-1. $\beta$-actin was used as loading control. B. Invasion assay of BxPc-3, Panc-1 and AsPc-1. The total number of invading cells was determined by counting the number of cells per field in 10 random fields, at $200 \times$ magnification. The average number of cells per field was then multiplied by a factor of 140 (growth area of membrane/field area viewed at 200x magnification (calibrated using a microscope graticule)). Insert: Colorimetric relative quantification of invading cells was also determined by elution of inserts with $0.33 \%$ acetic acid and spectrophotometrically quantified. Experiments performed in triplicate. 


\subsection{GSN and ALDH1A1 expression in panel of pancreatic cancer cell lines}

GSN and ALDH1A1 expression was detected through western blot in three other human pancreatic cancer cell lines, BxPc-3, Panc-1 and AsPc-1 (Fig. 6A). Fig. 6B shows the relative invasive potential of the cell lines. Both BxPc-3 and Panc- 1 expressed low levels of GSN compared to AsPc-1, which is less invasive. ALDH1A1 expression was stronger in BxPc-3 and Panc-1 than in AsPc-1 which corresponds to the high invasive abilities of BxPc-3 and Panc-1.

\section{Discussion}

In this study, proteins were analysed from culture medium conditioned by Clone \#3 and Clone \#8 in serum free conditions (SF) (to reduce the abundance of bovine serum proteins in the samples). 2D DIGE followed by MALDI-TOF MS analysis of SF CM\#3 and CM\#8 resulted in identification of 41 differentially expressed proteins. Bio-informatic analysis (GO STAT) was applied to all differentially abundant proteins between CM\#3 and CM\#8. Gene ontology (GO STAT) classified the proteins and their corresponding genes into gene categories. Although membrane-bound and secreted proteins are more likely to be cleaved and found in the circulation [12], our GO STAT analysis determined that most up-regulated and down-regulated proteins were involved in glycolysis, cytoplasm, cytosol and intracellular part. Proteins, such as heat shock proteins and actins, generally viewed as cytoplasmic, have been increasingly implicated in extracellular functions [13,14]. Eukaryotic protein secretion normally routes through the endoplasmatic reticulum (ER) and Golgi, ending up in a secretory vesicle fusing to the cell membrane. In addition, recent studies have shown that the non-classical secretory pathway works independently of the ER-Golgi network; the secreted proteins do not enter the ER and have not been glycosylated [15]. Nonclassical secretion by cell lines of the cytosolic green fluorescent protein (GFP) was shown experimentally [16]; export was not hampered by inhibitors of the classical secretory pathway, such as monensin and brefeldin A. Martin et al. [17] also identified many intracellular proteins from both the cytoplasmic and nuclear compartments from proteomics analysis of medium conditioned by the prostate cell line, LNCaP. During cell culture in serum free conditions, some cells will die, resulting in the release of intracellular proteins into the media. These intracellular proteins could serve as viable cancer-specific markers as cancer cells undergoing death can release proteins which can be detected in the circulation [18]. During our analysis we observed very little difference in the proliferation rate of cells grown in serum free conditions versus normal cell culture, therefore cell death was not a major contributor to the expression of intracellular proteins in the CM. Further analysis into the possible "secretion" mechanisms of these intracellular proteins would be of interest.

Two proteins, GSN and ALDH1A1, were chosen for siRNA silencing based on fold difference and $p$ value. GSN is a calciumbinding protein, which binds to and regulates actin filaments. GSN binds to the barbed ends of actin filaments and prevents capping [19]. Severing and capping of actin filament enhance the rate of cell motility and migration [20]. Gelsolin is located intracellularly in the cytoplasm and mitochondria [21] as well as extracellularly in the blood plasma [22]. The intracellular form, termed cytoplasmic, and the secreted form, termed plasma GSN, are derived from a single gene by alternative transcription initiation sites and differential sequencing [23]. Plasma GSN differs from cytoplasmic GSN, in that it is larger, contains 25 extra amino acids at its $\mathrm{NH}_{2}$ terminus, and is more positively charged [24], suggesting that it is synthesised more rapidly or catabolised more slowly [25]. Plasma GSN is removed from the cells more rapidly, consistent with a secreted protein, and only the plasma form of GSN is secreted in HepG2, a human hepatoma-derived cell line. Expression of GSN was lowest in the CM of the high invasive cell line, Clone \#3, and highest in the CM of the poorly invasive Clone \#8. RNAi technology was used to study GSN protein function in CM\#8. Using two independent GSN-siRNA target sequences, GSN protein expression was specifically down-regulated in Clone \#8 cells, resulting in decreased expression of GSN. Addition of CM from GSN-siRNA transfected Clone \#8 cells into the invasion chamber, increased invasion of Clone \#8. Our results suggest that GSN has functional effects on invasion in Clone \#8 cells. Decreased expression of GSN has been detected in several types of human cancers, including urinary bladder carcinogenesis [26], NSCLC [27], prostatic adenocarcinoma [28], breast [29] and ovarian cancer [30], suggesting a possible role as a tumour suppressor. Our results suggest that the invasion-inhibitory effects of CM\#8 may be in part due to GSN expression. GSN expression suppresses the activation of phospholipase C (PLC)/protein kinase C (PKCs) involved in phospholipid signalling pathways, thus inhibiting cell proliferation and tumourigenicity [31]. Furthermore, Tanaka et al. [32] functionally knocked down GSN expression by siRNA in the human mammary epithelial cell line, MCF10A, and suggested that GSN functions as a switch that controls E- and N-cadherin conversion via the transcription factor Snail. GSN knockdown led to an epithelial to mesenchymal transition, characterised by fibroblastic morphology, loss of contact inhibition, focus formation in monolayer growth and enhanced motility and invasiveness in vitro. Therefore, silencing GSN expression could possibly lead to tumour progression. However, GSN over-expression in 56\% of breast cancers was shown to be associated with over-expression of EGFR and HER2, as well as a more aggressive phenotype [33]. High GSN levels have also been identified as a negative prognostic factor in pulmonary carcinomas, stage I non-small cell lung carcinomas [34], where they have been linked to enhanced cellular motility. In pancreatic cancer, Ni et al [35] found reduced GSN expression in $71 \%(30 / 42)$ of pancreatic cancer cases compared to matched control tissues by immunohisochemistry. This reduction seemed to be dependent on the ubiquitin-proteasome dependent degradation of GSN. However, GSN expression was higher in lymph node positive pancreatic cancers compared to lymph node negative tumours. Thompson et al [36] reported that high levels of nuclear GSN correlated with reduced patient survival time, signifying re-emergence of GSN during the most aggressive metastatic stages of pancreatic cancer. Reduction in the level of GSN in pancreatic cancer cells decreased the motility of the cells, which differs from our results; the up-regulation of motility-modulating actin-capping proteins in pancreatic cancer cells may have different consequences for the motility of 
these cells at different stages of the metastatic process [36]. This study found GSN expression in the MiaPaCa-2 cell line, and showed that down-regulation of GSN decreased motility. In our model, both cytoplasmic and plasma GSN were detected by western blot and 2D-DIGE from the conditioned media of Clone \#8, the less invasive clonal population of MiaPaCa-2. Clone \#8 is a clonal population of MiaPaCa-2, with very different properties from Clone \#3, isolated at the same time. Furthermore, we found that down-regulation of plasma GSN expression in CM\#8 increased invasion of Clone \#8 cells. Thompson et al [36] detected cytoplasmic/nuclear expression of GSN in pancreatic cancer tissue specimens and cytoplasmic GSN in pancreatic cancer cell lines. The differences in the GSN isoforms detected between the two studies may explain why differing effects on invasion and migration were observed, however further studies are required to specifically clarify the roles of cytoplasmic and plasma GSN on migration and invasion in pancreatic cancer. A study detailing antibody microarray profiling of combined serum proteins associated with pancreatic cancer, showed a significant reduction of plasma GSN in pancreatic cancer serum compared to healthy controls [37], and plasma GSN expression was also decreased in lung cancer serum by proteomic profiling [38]. The mechanism by which GSN stimulates invasion by interacting extracellularly with cancer cells as detailed is not known. To further characterise function of GSN in this system, experiments involving addition of recombinant GSN protein into CM\#3 would be valuable, but highly purified GSN would be needed to generate useful results.

A novel protein identified as promoting the invasive abilities of pancreatic cancer cells is aldehyde dehydrogenase 1A1 (ALDH1A1). ALDH1A1 is an enzyme, belonging to the aldehyde dehydrogenase family of proteins which are involved in the conversion of aldehydes to their corresponding acids by $\mathrm{NAD}(\mathrm{P})^{+}$ dependent reactions [39]. ALDH1A1 is a cytosolic enzyme found in many tissues, including brain [40] and red blood cells [41]. ALDH1A1 expression has also been implicated in drug resistance, as ALDH1A1 levels were higher in metastatic tumours that did not respond to cyclophosphamide-based treatment than those that did respond to the regimen [42]. ALDH1A1 expression has also been reported in the lung cancer cell line, A549, where its expression along with ALDH1A3 was knocked down by RNAi and implicated in cyclophosphamide resistance [43]. Jelski et al. [44] also found that ALDH is expressed in pancreatic cancer cells and furthermore ALDH could also be detected in the sera of pancreatic cancer patients, although not significantly different between pancreatic cancer patients and healthy controls [45].

ALDH1A1 is highly expressed in CM\#3 compared to CM\#8. ALDH1A1 expression was reduced in CM\#3 through siRNA targeting three independent sequences of the ALDH1A1 gene. Addition of CM from ALDH1A1-siRNA transfected Clone \#3 cells into the invasion chamber reduced invasion of Clone \#3 cells. This is the first time that ALDH1A1 has been reported as a protein involved in pancreatic cancer cell invasion. Further research will be required to determine its role in the clinical setting

The expression of GSN and ALDH1A1 determined by western blot in the human pancreatic cancer cell lines, BxPc-3, Panc-1 and AsPc-1 corresponded to the invasive properties of the cells. A larger panel of pancreatic cancer cell lines would be required to confirm the link between the expression of these proteins and invasion status in pancreatic cancer. Han et al [46] found that GSN mRNA is expressed at low levels in a panel of nine pancreatic cancer cell lines compared to the normal pancreas using cDNA microarrays.

In conclusion, identification of released proteins from cancer cell lines may serve as an efficient method in the establishment of a panel of potential therapeutic targets and biomarkers correlating to invasion/metastatic cascade of pancreatic cancer. Future work will include examining the sera of pancreatic cancer patients to further demonstrate if GSN and ALDH1A1 have a diagnostic potential as biomarkers for pancreatic adenocarcinoma.

\section{Acknowledgement}

This work was supported by the Irish Higher Education Authority's Programme for Research in Third-Level Institutions (PRTLI) cycle 3 and 4.

\section{R E F E R E N C E S}

[1] Ferlay J, Autier P, Boniol M, Heanue M, Colombet M, Boyle P. Estimates of the cancer incidence and mortality in Europe in 2006. Ann Oncol 2007;18:581-92.

[2] Jemal A, Thomas A, Murray T, Thun M. Cancer statistics, 2002. CA Cancer J Clin 2002;52:23-47.

[3] Faivre J, Forman D, Esteve J, Obradovic M, Sant M. Survival of patients with primary liver cancer, pancreatic cancer and biliary tract cancer in Europe. Eur J Cancer 1998;34:2184-90.

[4] Negm RS, Verma M, Srivastava S. The promise of biomarkers in cancer screening and detection. Trends Mol Med 2002;8:288-93.

[5] Kuramitsu K, Nakamura Y. Proteomic analysis of cancer tissues: shedding light on carcinogenesis and possible biomarkers. Proteomics 2006;6:5650-61.

[6] Lundin J, Roberts PJ, Kuusela P, Haglund C. Prognostic significance of serum CA 242 in pancreatic cancer. A comparison with CA 19-9. Anticancer Res 1995;15:2181-6.

[7] Safi F, Schlosser W, Falkenreck S, Beger HG. Prognostic value of CA 19-9 serum course in pancreatic cancer. Hepatogastroenterology 1998;45:253-9.

[8] Tempero MA, Uchida E, Takasaki H, Burnett DA, Steplewski Z, Pour PM. Relationship of carbohydrate antigen 19-9 and Lewis antigens in pancreatic cancer. Cancer Res 1987;47:5501-3.

[9] Goggins M. Molecular markers of early pancreatic cancer. J Clin Oncol 2005;23:4524-31.

[10] Albini A, Iwamoto Y, Kleinman HK, Martin GR, Aaronson SA, Kozlowski JM, et al. A rapid in vitro assay for quantitating the invasive potential of tumor cells. Cancer Res 1987;47:3239-45.

[11] Alban A, David SO, Bjorkesten L, Andersson C, Sloge E, Lewis $\mathrm{S}$, et al. A novel experimental design for comparative two-dimensional gel analysis: two-dimensional difference gel electrophoresis incorporating a pooled internal standard. Proteomics 2003;3:36-44.

[12] Kulasingam V, Diamandis EP. Proteomic analysis of conditioned media from three breast cancer cell lines: a mine for biomarkers and therapeutic targets. Mol Cell Proteomics 2007;6:1997-2011.

[13] Altmeyer A, Maki RG, Feldweg AM, Heike M, Protopopov VP, Masur SK, et al. Tumor-specific cell surface expression of the-KDEL containing, endoplasmic reticular heat shock protein gp96. Int J Cancer 1996;69:340-9. 
[14] Wang H, Schultz R, Hong J, Cundiff DL, Jiang K, Soff GA. Cell surface-dependent generation of angiostatin4.5. Cancer Res 2004;64:162-8.

[15] Bendtsen JD, Jensen LJ, Blom N, Von Heijne G, Brunak S. Feature-based prediction of non-classical and leaderless protein secretion. Protein Eng Des Sel 2004;17:349-56.

[16] Tanudji M, Hevi S, Chuck SL. Improperly folded green fluorescent protein is secreted via a non-classical pathway. J Cell Sci 2002;115:3849-57.

[17] Martin DB, Gifford DR, Wright ME, Keller A, Yi E, Goodlett DR, et al. Quantitative proteomic analysis of proteins released by neoplastic prostate epithelium. Cancer Res 2004;64:347-55.

[18] Holdenrieder S, Stieber P. Apoptotic markers in cancer. Clin Biochem 2004;37:605-17.

[19] Kumar N, Tomar A, Parrill AL, Khurana S. Functional dissection and molecular characterization of calcium-sensitive actin-capping and actin-depolymerizing sites in villin. J Biol Chem 2004;279:45036-46.

[20] Cunningham CC, Stossel TP, Kwiatkowski DJ. Enhanced motility in NIH 3T3 fibroblasts that overexpress gelsolin. Science 1991;251:1233-6.

[21] Koya RC, Fujita H, Shimizu S, Ohtsu M, Takimoto M, Tsujimoto Y, et al. Gelsolin inhibits apoptosis by blocking mitochondrial membrane potential loss and cytochrome c release. J Biol Chem 2000;275:15343-9.

[22] Chaponnier C, Borgia R, Rungger-Brandle E, Weil R, Gabbiani G. An actin-destabilizing factor is present in human plasma. Experientia 1979;35:1039-41.

[23] Kwiatkowski DJ, Mehl R, Yin HL. Genomic organization and biosynthesis of secreted and cytoplasmic forms of gelsolin. J Cell Biol 1988;106:375-84.

[24] Kwiatkowski DJ, Stossel TP, Orkin SH, Mole JE, Colten HR, Yin HL. Plasma and cytoplasmic gelsolins are encoded by a single gene and contain a duplicated actin-binding domain. Nature 1986;323:455-8.

[25] Yin HL, Kwiatkowski DJ, Mole JE, Cole FS. Structure and biosynthesis of cytoplasmic and secreted variants of gelsolin. J Biol Chem 1984;259:5271-6.

[26] Tanaka M, Mullauer L, Ogiso Y, Fujita H, Moriya S, Furuuchi K, et al. Gelsolin: a candidate for suppressor of human bladder cancer. Cancer Res 1995;55:3228-32.

[27] Dosaka-Akita H, Hommura F, Fujita H, Kinoshita I, Nishi M, Morikawa T, et al. Frequent loss of gelsolin expression in non-small cell lung cancers of heavy smokers. Cancer Res 1998;58:322-7.

[28] Lee HK, Driscoll D, Asch H, Asch B, Zhang PJ. Downregulated gelsolin expression in hyperplastic and neoplastic lesions of the prostate. Prostate 1999;40:14-9.

[29] Winston JS, Asch HL, Zhang PJ, Edge SB, Hyland A, Asch BB. Downregulation of gelsolin correlates with the progression to breast carcinoma. Breast Cancer Res Treat 2001;65:11-21.

[30] Noske A, Denkert C, Schober H, Sers C, Zhumabayeva B, Weichert W, et al. Loss of Gelsolin expression in human ovarian carcinomas. Eur J Cancer 2005;41:461-9.

[31] Sagawa N, Fujita H, Banno Y, Nozawa Y, Katoh H, Kuzumaki N. Gelsolin suppresses tumorigenicity through inhibiting PKC activation in a human lung cancer cell line, PC10. Br J Cancer 2003;88:606-12.

[32] Tanaka H, Shirkoohi R, Nakagawa K, Qiao H, Fujita H, Okada F, et al. siRNA gelsolin knockdown induces epithelial-mesenchymal transition with a cadherin switch in human mammary epithelial cells. Int J Cancer 2006;118:1680-91.

[33] Thor AD, Edgerton SM, Liu S, Moore II DH, Kwiatkowski DJ. Gelsolin as a negative prognostic factor and effector of motility in erbB-2-positive epidermal growth factor receptor-positive breast cancers. Clin Cancer Res 2001;7:2415-24.

[34] Shieh DB, Godleski J, Herndon II JE, Azuma T, Mercer H, Sugarbaker DJ, et al. Cell motility as a prognostic factor in Stage I non-small cell lung carcinoma: the role of gelsolin expression. Cancer 1999;85:47-57.

[35] Ni XG, Zhou L, Wang GQ Liu SM, Bai XF, Liu F, et al. The ubiquitin-proteasome pathway mediates the downregulation of gelsolin protein levels in pancreatic cancer. Mol Med 2008 [Electronic publication ahead of print].

[36] Thompson CC, Ashcroft FJ, Patel S, Saraga G, Vimalachandran $D$, Prime W, et al. Pancreatic cancer cells overexpress gelsolin family-capping proteins, which contribute to their cell motility. Gut 2007;56:95-106.

[37] Orchekowski R, Hamelinck D, Li L, Gliwa E, vanBrocklin M, Marrero JA, et al. Antibody microarray profiling reveals individual and combined serum proteins associated with pancreatic cancer. Cancer Res 2005;65:11193-202.

[38] Okano T, Kondo T, Kakisaka T, Fujii K, Yamada M, Kato H, et al. Plasma proteomics of lung cancer by a linkage of multi-dimensional liquid chromatography and two-dimensional difference gel electrophoresis. Proteomics 2006;6:3938-48.

[39] Yoshida A, Rzhetsky A, Hsu LC, Chang C. Human aldehyde dehydrogenase gene family. Eur J Biochem 1998;251:549-57.

[40] Bhave SV, Hoffman PL, Lassen N, Vasiliou V, Saba L, Deitrich $\mathrm{RA}$, et al. Gene array profiles of alcohol and aldehyde metabolizing enzymes in brains of C57BL/ 6 and DBA/2 mice. Alcohol Clin Exp Res 2006;30:1659-69.

[41] Collard F, Vertommen D, Fortpied J, Duester G, Van Schaftingen E. Identification of 3-deoxyglucosone dehydrogenase as aldehyde dehydrogenase 1A1 (retinaldehyde dehydrogenase 1). Biochimie 2007;89:369-73.

[42] Sladek NE, Kollander R, Sreerama L, Kiang DT. Cellular levels of aldehyde dehydrogenases (ALDH1A1 and ALDH3A1) as predictors of therapeutic responses to cyclophosphamide-based chemotherapy of breast cancer: a retrospective study. Rational individualization of oxazaphosphorine-based cancer chemotherapeutic regimens. Cancer Chemother Pharmacol 2002;49:309-21.

[43] Moreb JS, Mohuczy D, Ostmark B, Zucali JR. RNAi-mediated knockdown of aldehyde dehydrogenase class-1A1 and class-3A1 is specific and reveals that each contributes equally to the resistance against 4-hydroperoxycyclophosphamide. Cancer Chemother Pharmacol 2007;59:127-36.

[44] Jelski W, Chrostek L, Szmitkowski M. The activity of class I, II, III, and IV of alcohol dehydrogenase isoenzymes and aldehyde dehydrogenase in pancreatic cancer. Pancreas 2007;35:142-6.

[45] Jelski W, Zalewski B, Szmitkowski M. Alcohol dehydrogenase (ADH) isoenzymes and aldehyde dehydrogenase (ALDH) activity in the sera of patients with pancreatic cancer. Dig Dis Sci 2007.

[46] Han H, Bearss DJ, Browne LW, Calaluce R, Nagle RB, Von Hoff $D D$. Identification of differentially expressed genes in pancreatic cancer cells using cDNA microarray. Cancer Res 2002;62:2890-6. 